\title{
Performance evaluation of sustainable agricultural-techno park development in Cigombong, West Java
}

\author{
Maesti Mardiharini*, Chandra Indrawanto, and Eni Siti Rohaeni \\ Indonesian Agency for Agricultural Research and Development (IAARD), Jln Tentara Pelajar No.10, \\ Bogor 16164, Indonesia
}

\begin{abstract}
One of the efforts to accelerate the flow of technological research results to users/farmers is through the development of Agricultural Techno Park (ATP). In this study, the performance evaluation of ATP development using cluster analysis was conducted by applying the Context, Input, Process, and Product (CIPP) model. The aims were to analyze the progress of ATP through clustering techniques and to formulate alternative strategy in the future. This study was conducted using a structured survey approach involving 76 farmers, April to June 2018, at the ATP Cigombong, West Java, Indonesia. The results of distance and similarity analysis showed that aspects of input and process had a closeness of satisfaction. Innovation assistance activities are not optimal, which should lead to becoming independent farmers. The future strategy has formulated context and product indicators in a participatory manner from the beginning, so that the target group understands and detects the progress. Farmers' needs must be identified from the beginning of ATP development to strengthen self-reliance of supporting facilities. ATP needs to formulate a new method in planning of innovation assistance. It is also important to develop new training (such as motivational training, technical and managerial skills).
\end{abstract}

\section{Introduction}

Agricultural development in Indonesia has the principles of independence and sustainability. One of which is realized through efforts to increase production and productivity per unit area of various commodities, as well as the added value developed from upstream to downstream. These efforts are realized through the transfer of agricultural technology from researchers/engineers to users/farmers. The problem is that technology transfer is still considered slow, not only in Indonesia, but almost all developing countries are experiencing the same problem. One of the efforts of the Indonesian government to accelerate the flow of technology and innovation to users is through the development of the Agricultural Science Park (ASP) and the Agricultural Technology Park (ATP). In general, ASP and ATP are a pilot area as well as a provider of agricultural technology [1].

ASP is more nuanced as a source of technological innovation that can be accessed by the user community, which is equipped with training facilities for people who want to apply

* Corresponding author: maesti m@yahoo.com 
existing technological innovations. Meanwhile, ATP is a vehicle for implementing direct technological innovation in the area of agricultural land belonging to the community, with intensive assistance from researchers and extension agents so that farmers can skillfully apply modern technology. Entering the third year (2018), it is targeted that ASP and ATP will lead to bring the innovation of research and assessment results closer to users. One indicator of the success of ATP development is shown by an increase in farmer income. This means that the technology must be adopted by farmers, and the role of innovation companion or extension services to deliver technology is very important.

Several research results showed that the development of ATP is able to accelerate the adoption of innovation by farmers/breeders, as well as increase the income of their farming or livestock business [2,3,4]. However, ATP development is also constrained by the management or performance of disseminating innovation to a wider range of users. In addition to accelerate innovation used by farmers, ATP also has potential as a tourism location. The development of agro-tourism in rural areas based on local communities is expected to provide many benefits $[5,6]$ stated that ATP is a way to improve farmer welfare and increase the competitiveness of products. Furthermore, it was revealed that ATP can be used as a tourist destination which aims to broaden the horizons, knowledge, experience, recreation and agricultural business of food crops, horticulture, plantations, fisheries, animal husbandry, forests and aquatic resources for the visitors.

The development of ATP must be well planned, including sorting or classifying the required aspects to be emphasized on the priority scale. This grouping technique can be assisted by means of a cluster analysis tool, making it easier for policy makers to plan, implement, and evaluate for wider ATP development. One of the evaluation models is the Context, Input, Process, and Product (CIPP) model. The uniqueness of this model is that each type of evaluation is related to the decision-making tool regarding the planning and operation of a program $[3,6]$. The CIPP model is a decision-holder-oriented model $[7,8]$ through the application of the evaluation model combined with clustering analysis. This model will provide a comprehensive evaluation result format. One ATP that implements an integrated plant-livestock innovation is ATP Cigombong in Bogor Regency. Performance evaluation of ATP development using clustering technique has never been applied. Therefore, the aims of this study were to identify the characteristics of farmers / breeders and their perceptions of the performance of ATP Cigombong using the CIPP model and to analyze the performance of ATP Cigombong using clustering techniques.

\section{Methodology}

\subsection{Location, time and approach}

This study was conducted from April to June 2018. The study location was the ATP Cigombong area, in Tugujaya Village, Cigombong Sub-district, Bogor Regency, West Java Province, Indonesia. The location was selected purposively based on the consideration of ATP which implements the innovation of crop-livestock integration that was developed by the Indonesian Agency for Agricultural Research and Development (IAARD).

This study was conducted using a quantitative approach and enriched with qualitative data/information. Confirmation at the field level was carried out based on the foundation of developed theories and concepts. Stages of activity through the application of the CIPP performance evaluation model were performed according to methods developed by [9]. There are four stages, i.e., (1) the context stage is carried out by evaluating the enhancement of the capacity of target groups for programs and government regulations; (2) the input stage is carried out through evaluation of the ATP manager competences, the conditions of the target 
groups, materials for counselling/mentoring, facilities and infrastructure; (3) the process stage is carried out by evaluating the activeness of extension agents/assistants and the activeness of target groups; and (4) the product stage is carried out through evaluation of the results of activities $[9,10]$.

\subsection{Data collection and analysis}

The subjects in this study were: (1) assistants/extension agents in the ATP program and (2) Farmers and breeders as the target groups of the ATP program. The study population was members of the farmer groups in the Tugujaya Village who were supervised by ATP Cigombong. There were three groups of farmers/breeders who had been coached, i.e., The Food Crop Farmer Group (32 farmers), The KUB Chicken Farmer Group (22 farmers), and The Sheep/Goat Farmer Group (22 farmers). The unit of analysis in this study was the farmer/breeder. The total number of respondents was 76 farmers/breeders (census method).

Primary data was directly obtained, either by group interviews or interviews with key informants (community leaders and ATP managers), as well as with respondents. Secondary data was obtained by literature search and data/information from related agencies.

The study instrument was in the form of two type questionnaires, i.e., (1) semi-structured questionnaire for group interviews and assistants/extension agents in the ATP program containing questions and statements related to the materials provided to farmers/breeders, as well as planning and implementation of ATP activities; and (2) structured questionnaire for respondents related to ATP management competencies, coaching materials, implementation and evaluation of ATP activities.

The results of the validity test using the Pearson Correlation showed that of the 47 questions there were 35 valid questions (79.54\%). The reliability testing of the instrument was performed using the Cronbach's alpha formula because this research instrument was in the form of a questionnaire and a stratified (likert) scale. The reliability test results showed a Cronbach's alpha value of 0.904 . This indicated that overall, the respondents' answers were sufficient and consistent.

The first aim of this study was answered using the cross tabulation, calculated using Microsoft Excel software. The description of the CIPP aspect was determined using the average and the interval categories as the criteria reference. There were 4 (four) assessment criteria, i.e., Very Poor, Poor, Good, and Very Good. Each of these criteria was based on the respondents' average answers or perceptions of the questions that refer to the indicators and research parameters (Table 1).

Table 1. Interval and categories of performance evaluation of ATP Cigombong for the context, input, process, and product (CIPP) aspects

\begin{tabular}{|l|c|c|}
\hline No. & Evaluation interval & Rating category \\
\hline 1. & $1.00-1.49$ & Very poor \\
\hline 2. & $1.50-2.49$ & Poor \\
\hline 3. & $2.50-3.49$ & Good \\
\hline 4. & $3.50-4.00$ & Very good \\
\hline
\end{tabular}

The second aim of this study was answered using the Pearson distance cluster analysis with the Single Linkage method. According to [11], Pearson distance is an extension of the Euclidean distance by taking into account the correlation between objects. The single linkage method classifies two objects that have the closest distance first. The distance between groups $(i, j)$ and $k$ is: $d(i, j) k=\min (d i k, d j k)$, formulated as the Pearson Distance as follows 


$$
d_{i j}=\sqrt{\sum_{k=1}^{p} \frac{\left(x_{i k}-x_{j k}\right)^{2}}{\operatorname{var}\left(x_{k}\right)}}
$$

Correlation distance Absolute correlation distance

$$
\begin{aligned}
& : d i j=1-r i j \\
& : d i j=1-|r i j|
\end{aligned}
$$

The software used in this cluster analysis was Minitab. Minitab is a provider of desktop software fo data analysis, data management, data visualization, data mining (also known as predictive analaysis), and quality control.

\section{Results and discussion}

\subsection{General description of areas and characteristics of respondents}

The ATP Cigombong was established based on an agreement with the Bogor Regency Regional Government. The location of this ATP is in Tugujaya Village, Cigombong Subdistrict, Bogor Regency. The potential business development in this area is the cultivation of food crops integrated with livestock and fish farming. The types of livestock that are mostly cultivated are sheep and goats. Farmers have not performed intensive farming of chickens and this is the potential to be developed in the future.

The development of Bogor ATP is the responsibility of the Ministry of Agriculture together with Bogor Regency government and Bogor Agricultural University (IPB). The Decree of the Head of IAARD number 164.1/2015 concerning the person in charge of the Agricultural Science and Technology Park of IAARD in 2015 stipulates that the Bogor Agricultural Technology Transfer Management Center as the representative executor of IAARD. The coordination of the three institutions was carried out in planning activities at the activity site and in the surrounding villages, especially in the preparation of the grand design and master plan for the development of the ATP Cigombong. The officials of Tugu Jaya, Pasir Jaya and Cisalada villages were also involved in the planning process.

The characteristics of the respondents in this study indicated that $96.7 \%$ were male, with a predominantly productive age range of 31-60 years and tend to be older of $>60$ years. Respondents' education was generally still low, i.e., $53.3 \%$ was graduated from elementary school and $16.7 \%$ did not finish primary school. Education is actually important because sufficient education can affect the success of farming and increase the ability of farmers to make changes [12].

\subsection{Perceptions of farmers and breeders on the performance of ATP Cigombong}

Perceptions of farmers and breeders about the performance of ATP Cigombong on the aspects of context, input, process and product (CIPP) were generally rated as "Good" (60 - $90 \%$ ) and around 10 - $40 \%$ rated "Very Good" (Table 2). The various programs of innovation assistance, training and apprenticeship organized by ATP Cigombong were very diverse and related to agricultural innovations needed by the farming community in the Cigombong area, or more broadly in Bogor Regency. $40 \%$ of respondents gave a "Very Good" rating, especially for the input aspect. This is understandable because the inputs referred to were various facilities, including a classroom atmosphere, training materials, as well as demonstration plots that were available and easily accessible to farmers/breeders around the ATP Cigombong area. In addition, this evaluation can also be determined from another perspective. According to $[12,13]$ the training program is one of the factors influencing 
participants to make changes in their farming activities. The training provides an open opportunity for interaction between participants and resource persons, and this can help to change values and attitudes towards an innovation.

Table 2. Frequency and percentage of respondents in the performance evaluation of ATP Cigombong in the CIPP aspect in 2018

\begin{tabular}{|l|c|c|r|r|r|r|}
\hline No. & Evaluation & Rating & \multicolumn{4}{|c|}{ CIPP Evaluation Aspect } \\
\cline { 4 - 7 } & interval & category & Context & Input & Process & \multicolumn{1}{|c|}{ Product } \\
\hline 1. & $1.00-1.49$ & Very poor & 0 & 0 & 0 & 0 \\
\hline 2. & $1.50-2.49$ & Poor & 0 & 0 & $3(4.0)$ & 0 \\
\hline 3. & $2.50-3.49$ & Good & $68(89.5)$ & $46(60.5)$ & $65(85.5)$ & $68(89.5)$ \\
\hline 4. & $3.50-4.00$ & Very good & $8(10.5)$ & $30(39.5)$ & $8(10.5)$ & $8(10.5)$ \\
\hline
\end{tabular}

Note: The number in brackets ( ) is the percentage of the total respondents

The research results by [6] at ATP based on sheep innovation in Garut Regency, West Java, at ATP based on rice commodity innovation in Aceh Besar Regency, Nangroe Aceh Darusalam Province, [5,14] at ATP based on cocoa commodity in Gunung Kidul Regency, Yogyakarta Special Region also showed that farmers/breeders assess positively about the presence of ATP in their area. Various inputs were given at the beginning of the ATP development program to farmers/breeders to develop their farming/livestock business.

The results of the cross tabulation (crosstab) analysis in this study showed the perceptions or performance evaluation of ATP Cigombong on the CIPP aspects from respondents based on age groups. There was a tendency that the younger age group $(<30$ years old $)$ rated a "Very Good" score (> 3.50) (Table 3).

Table 3. Respondents' perceptions by age group on the performance of ATP Cigombong in the CIPP aspect in 2018

\begin{tabular}{|c|c|c|c|c|c|}
\hline \multirow{2}{*}{ No. } & Respondent Age & \multicolumn{4}{|c|}{ CIPP Evaluation Aspect } \\
\cline { 3 - 6 } & Group (years) & Context & Input & Process & Product \\
\hline 1. & $\leq 30$ & 3.29 & 3.70 & 3.38 & 3.22 \\
\hline 2. & $31-60$ & 3.03 & 3.26 & 3.04 & 2.99 \\
\hline 3. & $>60$ & 3.03 & 3.12 & 3.03 & 2.93 \\
\hline & Total Average & 3.08 & 3.34 & 3.11 & 3.03 \\
\hline
\end{tabular}

In average, for the age more than 60 as categories as lagging. The young age group became interested in the innovations introduced by ATP, especially by paying attention to the input aspect. This youth group also rated "Good" for other aspects (context, process and product). This indicated that the young age group was starting to become interested in agriculture. This is in accordance with [15] that age and education have a significant effect on farming decision making. The research results reported by [16,17] also showed a significant relationship between socio-economic characteristics such as age in the success of agricultural training program.

The respondents' perceptions based on farmer/breeder groups on the performance of ATP Cigombong in the CIPP aspects showed that the group of chicken breeders gave relatively high scores between "Good" and "Very Good" in all aspects of CIPP (Table 4). 
Table 4. Respondents' perceptions based on farmer / breeder groups on the performance of ATP Cigombong in the CIPP aspect in 2018

\begin{tabular}{|c|l|c|c|c|c|c|}
\hline \multirow{2}{*}{ No. } & \multirow{2}{*}{ Respondent group } & \multicolumn{5}{|c|}{ CIPP Evaluation Aspect } \\
\cline { 3 - 7 } & & Context & Input & Process & Product & CIPP \\
\hline 1. & Food crops farmers group & 2.77 & 2.84 & 2.79 & 2.76 & 2.79 \\
\hline 2. & Sheep/goat farmer group & 3.03 & 3.62 & 3.15 & 2.96 & 3.19 \\
\hline 3. & KUB Chicken farmer group & 3.45 & 3.55 & 3.38 & 3.37 & 3.44 \\
\hline \multicolumn{2}{|l}{ Average } & 3.08 & 3.34 & 3.11 & 3.03 & 3.14 \\
\hline
\end{tabular}

The food crop farmer groups gave relatively low scores with an average score below 3.0 in all aspects of the CIPP, although they were still in the category of Good performance. In the field of chicken breeders, it is understood that the business conditions are classified as young business. The chicken farming business in the Cigombong area is also relatively new, and the type of chicken being raised is also relatively new, i.e., the IAARD superior native chicken (KUB Chicken). This is a challenge for young breeders, and there are even four young villagers who have just tried to raise chickens. Previously they were farmers of food crops and secondary crops. KUB chicken for Kampung Unggul Balitbangtan (improved kampung chicken for the Indonesia Agency for Agriculture Research and Development) [1].

\subsection{Cluster analysis of context, input, process, and product aspects}

The cluster analysis in this study was carried out in the evaluation model of CIPP aspects. The four aspects measured were the distance proximity, i.e., Context (C), Input (I), Process $(\mathrm{P})$, and Product $(\mathrm{P})$. The relationships among these four aspects were analyzed using the Pearson correlation (Table 5). The results of the Pearson distance correlation showed that the Context and Product aspects had the highest value of 0.870 (have a very close relationship), then the second highest correlation was the Input and Process aspects of 0.675 (significant at the level of $\alpha=0.01$ ).

Table 5. Pearson distance correlation in the cluster analysis of the CIPP aspects' evaluation model

\begin{tabular}{|l|c|c|c|c|}
\hline \multicolumn{1}{|c|}{ Monitoring aspect } & Context & Input & Process & Product \\
\hline Context & 1.000 & & & \\
\hline Input & $0.569(0.001)^{* *}$ & 1.000 & & \\
\hline Process & $0.570(0.001)^{* *}$ & $0.675(0.000)^{* *}$ & 1.000 & \\
\hline Product & $0.870(0.000)^{* *}$ & $0.518(0.003)^{* *}$ & $0.552(0.002)^{* *}$ & 1.000 \\
\hline
\end{tabular}

** Significant at the level of $\alpha=0.01$

The results of cluster analysis using Minitab software in this study are in line with the correlation values above. Dendrogram as a result of the cluster analysis (Fig.1) shows that the Context and Product aspects are in one cluster. 


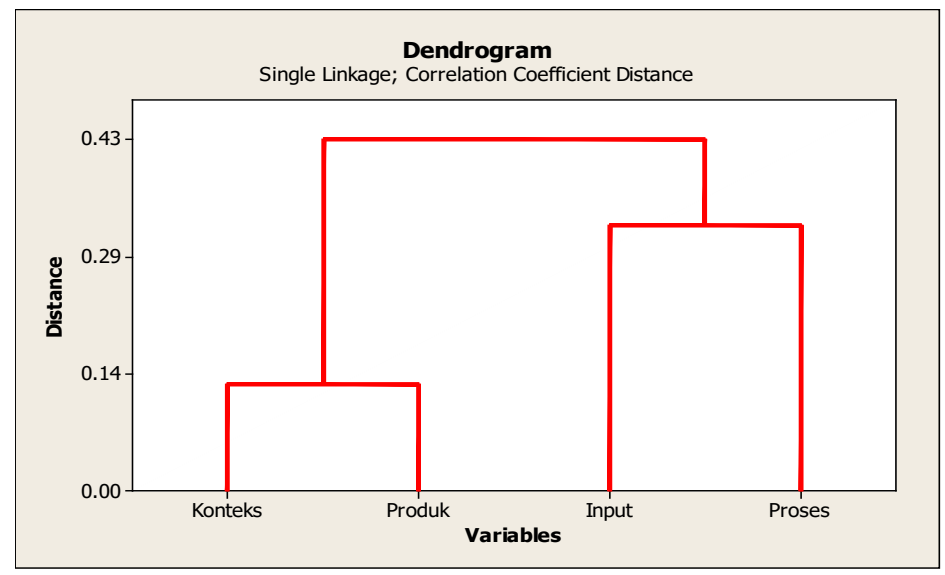

Fig. 1. Dendrogram for cluster analysis of the distance level of respondent's satisfaction in the performance evaluation of ATP Cigombong in 2018.

The value of the Pearson correlation distance between the levels of respondent's satisfaction in these two aspects was almost similar and relatively very close of 0.13 . Likewise, the proximity of the Input and Process aspects had a Pearson correlation distance value of 0.33 . This indicated that the respondent's satisfaction with the existence of ATP is closely related to the results that can be perceived or seen directly by farmers/breeders. This shows that the presence of ATP has a good influence in the dissemination of information to the closest community [3].

Dendrogram in Figure 1 showed the similarity value among clustered aspects. The cluster of context and product aspects had a similarity value close to $93.52 \%$. This was higher than the input and process aspects which had a similarity value of $83.73 \%$ (Fig. 2).

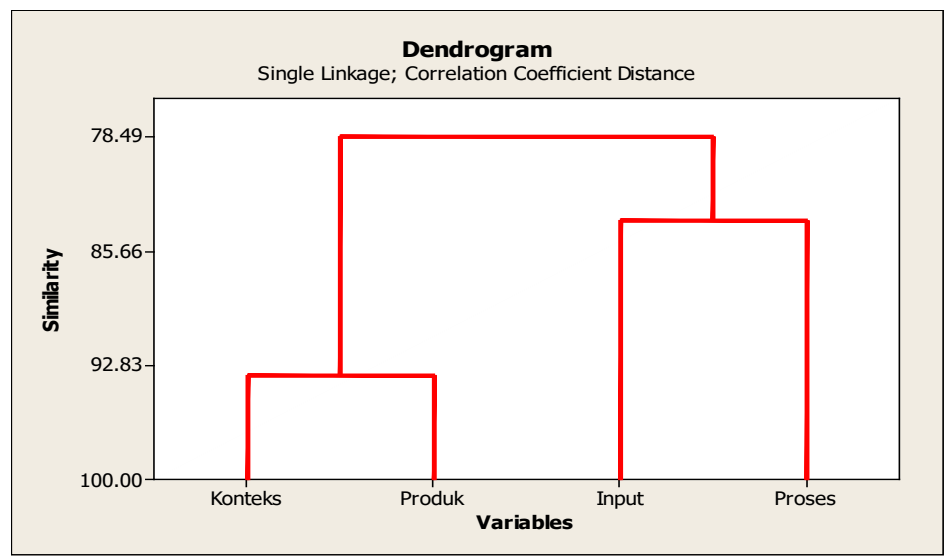

Fig. 2. Dendrogram for cluster analysis of the similarity level of respondent's satisfaction in the performance evaluation of ATP Cigombong in 2018.

The similarity values are presented in Table 6 . The results of the analysis using SPSS and Minitab software's showed that the input and process aspects had a close satisfaction in terms of distance and similarity. The process is the implementation of an activity and the work mechanism of a program in achieving goals [1]. Evaluation of the success level of ATP activities can be determined from the results of the process analysis (Table 6). The implementation of ATP activities is realized by providing various means or inputs for 
farming/livestock business activities, and the implementation process is also designed to be easily understood by farmers. This puts the input and process aspects into harmony/similar satisfaction scores.

Table 6. Results of cluster analysis for Context, Input, Process, and Product aspects Correlation Coefficient Distance, Single LinkageAmalgamation Steps

\begin{tabular}{|c|c|c|c|c|c|c|}
\hline Step & $\begin{array}{c}\text { Number } \\
\text { of } \\
\text { clusters }\end{array}$ & $\begin{array}{c}\text { Similarity } \\
\text { level }\end{array}$ & $\begin{array}{c}\text { Distance } \\
\text { level }\end{array}$ & $\begin{array}{c}\text { Clusters } \\
\text { joined }\end{array}$ & $\begin{array}{c}\text { New } \\
\text { cluster }\end{array}$ & $\begin{array}{c}\text { Number of } \\
\text { obs.in new } \\
\text { cluster }\end{array}$ \\
\hline 1 & 3 & 93.5242 & 0.129517 & 1 with 4 & 1 & 2 \\
\hline 2 & 2 & 83.7354 & 0.325292 & 2 with 3 & 2 & 2 \\
\hline 3 & 1 & 78.4950 & 0.430100 & 1 with 2 & 1 & 4 \\
\hline
\end{tabular}

The reality in the field showed that the development or growth of ATP as a new approach in the effort to accelerate the adoption of innovation was not yet fully understood by the target groups. The existence of ATP, which was expected as a medium of learning and the creation of young entrepreneurs in the agricultural sector, also seems not as expected. The context or substance of the program and the expected outcomes of this program were not yet understood, so the satisfaction score for these two aspects was still low. Tracing the process of implementing activities in the first two years, the target group felt that ATP activities were the same as other government programs, like technology dissemination.

In relation with the impact of adoption process, the research results by [17] in Ghana stated that the low adoption of agricultural technology causes low agricultural productivity. Factors that significantly influence farmers' technology adoption decisions are land area, benefits from technology, access to credit and agricultural extension assistance. The decision to adopt agricultural technologies also depends on the farmer's socio-economy and the effectiveness of agricultural institutions. The acceleration of the technological innovation's adoption can be helped and supported by the presence of local farmers (in ATP locations) who have the influence to disseminate information or innovation [6].

Consistent cluster analysis helps to explain this phenomenon. Zhang [9] used this technique in social research by creating a hierarchically clustered and latent class model. The results of this study can explain the advantages of using this analysis compared to manual clustering, so that it can be used as a benchmark in improving program implementation by giving greater emphasis to certain clusters. Different results for seed dissemination [3], where the values associated with the context and product aspects are higher than the input and process. This is understandable because in dissemination for inputs such as rice seeds, the target group has understood the essence of the dissemination program from the beginning.

Meanwhile, the results of this study showed that for the introduction of a new concept such as accelerating the adoption of innovation through ATP, the target groups must have the same understanding of the objectives and the expected outcomes of the activities from the initial ATP development. In addition, indicators related to context and products should have also been formulated together from the beginning. Therefore, the target group can better understand the indicators and can determine progress in implementing activities in terms of the context and the final goals. This is also revealed from the research results of $[8,10]$; that for similar programs it is necessary to adjust the approach for evaluating a program using analysis starting from the planning, implementation, and the evaluation of the results.

The use of cluster analysis tools is very helpful in grouping observation data on variables that show the same phenomenon, as well as correlation analysis can help in determining the relationship among variables. The factor that needs to be improved in the use of this analysis is the accuracy in grouping variables. Fortunately, in this study, the target group is relatively homogeneous, making it easier to determine the grouping of variables. 


\subsection{Recommendations for future Agricultural Technology Park development policy}

Based on the results of CIPP analysis and cluster analysis, it reveals that the level of satisfaction with the implementation of ATP performance in terms of context, input, process, and product aspects was generally good and very good. However, when viewed partially, it shown that only the dominant input and process was very satisfying. This can be understood because ATP as a strategic government activity is flooded with adequate facilities and activity inputs. Meanwhile, in terms of the process of implementing activities, it was still slow due to the limited number of permanent staff and personnel that meet the required qualifications for ATP.

In the future, ATP needs to involve more partners from the academic side, in this case IPB University, Bogor, which is expected to support the existence of ATP through the support of experts in line with the spirit of ATP for accelerating the delivery of innovation in the form of developing innovation-based business activities. As the characteristics of farmers in various locations, some farmers involved in ATP activities have low education, and community groups cannot be accommodated in industrial activities around the ATP activity sites. Therefore, efforts to grow motivation and be able to help themselves become the starting point for all undertaken activities.

Another aspect that distinguishes ATP activities from other farmer groups is the orientation of the market-based business, and this also distinguishes ATP from extension activities in general. The plasma and core patterns developed by ATP Cigombong in the development of animal husbandry activities were a form of incubation with a joint development pattern between nucleus and plasma. As a business-oriented educational institution, the ATP as the core must also develop as a business institution that engages the plasma in mutually beneficial activities. This factor needs to be supported by good management and human resources who have a business spirit and are responsible. Through the above approaches, in terms of contents and products, the farmers should show a high level of satisfaction or a dominant excellent value. Satisfaction with input and process was still dominant indicating that the extension pattern was not fully oriented towards strengthening the target groups, and the results were not immediately perceived by the target groups. The dominance of satisfaction with input and process also showed that extension activities at ATP were still the same as other agricultural extension services, which provided farmers with various facilities and conveniences, so that their dependence on the assistance was very dominant.

Efforts to improve ATP development in the future are the farmer groups will be educated independently using the plasma core pattern and the direct payment for harvest mechanism. Group members must be serious and successful in implementing the ATP program. Therefore, they are able to foster good relations with market players and become a new nucleus that can foster new plasma as a form of program replication. In order for this program to run well, ATP managers must be able to embrace business actors as ATP's strategic partners or core who have been independently assisted by ATP. The performance arrangement is performed together among ATP, partners and the fostered group or plasma. The basis of the ATP performance is to make the target groups as independent business actors and be able to provide welfare for the farmer groups. To achieve this goal, it is necessary to formulate the forms of required training, starting from motivation, technical skills, managerial skills and the ability to enter the market or create a new market. Access to capital and main supporting facilities is a determining component that is often overlooked in conventional extension activities. 


\section{Conclusions}

The implementation of the ATP program is still dominant as a pilot activity that provides all inputs to attract farmers' participation in efforts to accelerate innovation adoption. Until the third year of the implementation various activities with farmers were still dominant in the form of providing assistance from ATP. With such a pattern, the goal of ATP was not optimal which should lead farmers to become independent actors and be able to establish profitable businesses for themselves, so that it will attract the participation of other parties. The cluster analysis and the evaluation of the CIPP model carried out in the implementation of the ATP Cigombong revealed a good performance of the ATP. The results of the distance and similarity analysis showed that the input and process aspects had closeness to satisfaction in terms of distance and similarity.

In the future, the performance arrangement should be performed together among ATP, partners and the assisted group or plasma. To achieve this goal, from the beginning of ATP development, indicators related to the context and products must be formulated together, so that the target group can better understand and can determine the implementation progress in terms of the context and the ultimate goal of ATP development activities.

Acknowledgments. Sincere thanks for Mrs. Dede Zaenab who has assisted in data collection in the field, as well as for Mr. Amita Rahmat who has taken the time to consult on data processing and interpretation.

\section{References}

1. Kementerian Pertanian. 'Pembangunan dan Pengembangan Taman Sains dan Teknologi Pertanian ( TSTP )', in Badan Penelitian dan Pengembangan Pertanian, p. 97. (2016)

2. H. Finch, Journal of Data Science, 3, 1 (2005)

3. K. Hakan, Seval, Procedia - Social and Behavioral Sciences. Elsevier B.V., 15 (2011)

4. I. Fatmal, S. Kasimin, A. Nugroho, International Journal of Multicultural and Multireligious Understanding, 7, 1 (2020)

5. I. Waspada. Jurnal Geografi, 8, 1 (2008)

6. A. Gunarto. Jurnal Sains dan Teknologi Indonesia, 17, 2 (2015)

7. F.Y. Tayibnapi. Evaluasi Program. (Jakarta: PT. Rineka Cipta. Kementrian Pendidikan dan Kebudayaan, 2000)

8. J.A. Opateye. Nigeria Journal of Education, Health and Technology Research (NJEHETR). 7 (2015)

9. G. Zhang. et al. 'Using the CIPP Evaluation Model as a Comprehensive Framework', 15, 4 (2011)

10. L. Kaufman, P.J. Rousseeuw, Finding Groups in Data: An Introduction to Cluster Analysis. (Wiley, New York,1990)

11. S. Kilpatrick. The Journal of Agricultural Education and Extension, 7, 2 (2000)

12. K. Singh, R. Peshin, S. Kaur, Journal of Agriculture and Rural Development in the Tropics and Subtropics, 111, 2 (2010)

13. A.S. Coster, M.I. Adekoya, Research Journal of Social Sciences, 1, 5 (2010)

14. S. Iskandar, T. Sartika. KUB Chicken: "The First Indonesian Kampung Chicken Selected for Egg Production". Proceedings of the 16th AAAP Animal Science Congress Vol. II 10-14 November 2014, Gadjah Mada University, Yogyakarta, Indonesia: 157160. (2014)

15. A. Pratiwi, A. Suzuki. Economic Structures: 6-8. (2017)

16. A. Faqih, S. Mutmainah, R. Wiradinata, Jurnal Agrijati, 9, 7 (2016)

17. M.A. Akudugu, E. Guo, S.K. Dadzie, Journal of Biology, Agriculture and Healthcare, 2 , 
3 (2012) 